\title{
A gestão da Bacia do Alto Paraguai: a participação dos grupos de interesse na formulação do marco legal do Pantanal de Mato de Grosso
}

\author{
Silvano Carmo de Souza \\ Doutorando no programa de Ciências Ambientais da Universidade Federal de São \\ Carlos. Mestre em Ciências Ambientais pela Universidade do Estado de Mato Grosso. \\ Professor do Instituto Federal de Educação, Ciência e Tecnologia de Mato Grosso - \\ Campus Cáceres Olegário Baldo.
}

\section{Carlos Teodoro José Hugueney Irigaray}

Pós-doutor em Direito pela Universidade da Flórida. Doutor em Direito pela UFSC. Mestre em Direito e Estado pela UFSC. Professor associado da UFMT. Procurador do Estado de Mato Grosso.

\begin{abstract}
Sumário: 1. Introdução; 2. Considerações metodológicas; 3. Um breve relato sobre a tramitação das minutas; 4. Participação nas audiências públicas: demandas e encaminhamentos do Estado/Mercado; 5 . Algumas considerações. 6. Referências.
\end{abstract}

\section{Introdução}

O Pantanal é uma das maiores extensões de áreas úmidas contínuas do planeta. Está localizado no centro da América do Sul, na Bacia Hidrográfica do Alto Paraguai. Sua área é de $138.183 \mathrm{~km}^{2}$, com $65 \%$ de seu território no estado de Mato Grosso do Sul e 35\% em Mato Grosso. Foi considerado: "Sítio Ramsar", "Patrimônio Mundial da Unesco" e "Reserva da Biosfera". Títulos que, para serem mantidos, impõem ao poder público a efetivação de uma gestão de fato participativa, integrada e sustentável; que englobe os aspectos sociais, ecológicos, econômicos e culturais da região.

No Pantanal, além da beleza natural e da rica biodiversidade, destaca-se a diversidade de povos e comunidades que nele vivem; povos e comunidades que se relacionam em função de uma ética tradicional ribeirinha pantaneira ${ }^{1}$. Entre

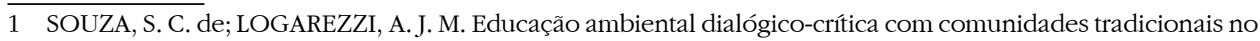


estas pessoas estão os povos e as comunidades tradicionais pantaneiras que desenvolvem, artesanalmente, a agricultura familiar, a pesca de subsistência e profissional, a pecuária, a prestação de serviços ao setor do turismo, o extrativismo, etc.

Também, mas de modo diverso, o Pantanal é ocupado por grandes empreendimentos do agronegócio, do setor energético, do trade turístico, da mineração, da navegação em grande escala, etc. Ao longo das últimas décadas, em função da ausência de uma legislação estadual e federal que de fato contemplasse a realidade sociocultural, ecológica e geológica da região, estamos experienciando o avanço de empreendimentos que ameaçam a estabilidade socioambiental do bioma - especialmente e de forma intencional ocasionando a invisibilidade de suas gentes.

Embora nossa Constituição estabeleça que a utilização dos recursos naturais no Pantanal, enquanto área de patrimônio natural, deve se dar, na forma da lei, dentro de condições que assegurem a preservação do meio ambiente (art. 225 § $4^{\circ}$ ), decorridos quase trinta anos desde a promulgação da Constituição Federal, aguardamos a aprovação de uma lei federal que possa delinear a gestão da maior área úmida do planeta e enfrentar os graves problemas ambientais que a ameaçam.

Visando suprir essa lacuna legal, o então senador Blairo Maggi apresentou no Senado Federal um Projeto de Lei (PLS 750), ainda em tramitação, tomando como referência a Lei Estadual n ${ }^{\circ} 8.830$, de 2008, que define a Política Estadual de Gestão e Proteção à Bacia do Alto Paraguai no Estado de Mato Grosso.

Certamente que na tarefa de construir um marco regulatório para assegurar a conservação desse patrimônio nacional, é imperativo reconhecer que no Pantanal vivem populações tradicionais que há mais de dois séculos promovem uma utilização sustentável dos recursos naturais e que, por isso, devem ser ouvidas nesse processo legislativo, certamente sem excluir outros grupos de interesse que também podem contribuir para que a lei federal a ser aprovada não enfrente resistências em sua implementação.

Essa experiência foi utilizada no processo que precedeu a elaboração da lei estadual acima referida, e é analisada neste artigo, a partir de uma abordagem interdisciplinar e com vistas a desvelar e enfrentar dialogicamente esta realidade tendo como base as Ciências Ambientais, visando detalhar como se deu a participação na elaboração do Marco Regulatório do Pantanal, no estado de Mato Grosso.

Pantanal de Mato Grosso: a solidariedade e os enfrentamentos nas práticas sociais. Ambiente e Educação, Revista de Educação Ambiental, 2016, no prelo. 
Este estudo permitiu identificar quais setores da sociedade civil tiveram suas demandas contempladas no processo legislativo que culminou com a sanção da citada Lei Estadual n. 8.830, de 2008, no estado de Mato Grosso.

Este artigo é um excerto de nossa dissertação de mestrado, desenvolvida no programa de Ciências Ambientais da Universidade do Estado de Mato Grosso entre os anos de 2006 e 2008 sob orientação do professor Dr. Carlos Teodoro José Hugueney Irigaray. Aqui, trataremos especificamente sobre três aspectos sobre os quais a/o leitora/or poderá encontrar informações mais pormenorizadas no texto Proteção Jurídica do Pantanal: a construção do marco regulatório no estado de Mato Grosso. ${ }^{2}$

À luz do referencial teórico-metodológico de Freire ${ }^{3}$, Grimble e Chan ${ }^{4}$ e Chevallier ${ }^{5}$ explicitaremos quais stakeholders atuaram no processo de formulação da Lei de gestão da Bacia do Alto Paraguai; também identificaremos quais demandas foram contempladas na norma sancionada.

\section{Considerações metodológicas}

A teoria da ação dialógica ${ }^{6}$ - proposta por Paulo Freire na década de setenta - está fundada no diálogo como sendo algo próprio da natureza humana, o autor afirma que o diálogo é:

[...] parte da própria natureza histórica dos seres humanos. É parte de nosso progresso histórico do caminho para nos tornarmos seres humanos. [...] é uma espécie de postura necessária, na medida em que os seres humanos se transformam cada vez mais em seres criticamente comunicativos. [...] O diálogo sela o relacionamento entre os sujeitos cognitivos, podemos, a seguir, atuar criticamente para transformar a realidade.?

Depreende-se dessa concepção que processos participativos devem garantir a participação efetiva de todas/os as/os envolvidas/os nos espaços

$\overline{2}$ SOUZA, S. C. de. Proteção Jurídica do Pantanal: a construção do marco regulatório no estado de Mato Grosso. 2008. 205p. Dissertação (Mestrado)-Programa de pós-graduação em Ciências Ambientais. Unemat, Cáceres: 2008.

3 FREIRE, P. Criando métodos de pesquisa alternativa. Aprendendo a fazê-la através da ação. In: BRANDÃO, C. R. (Org.). Pesquisa participante. 4. ed. São Paulo: Brasiliense, 1999. p. 34/41.

4 GRIMBLE, R; CHAN, M-K. Stakeholder analysis for natural resource management in developing countries. In: Natural resources forum. Blackwell Publishing Ltd., 1995. p. 113-124.

5 CHEVALIER, J. Stakeholder analysis and natural resource management. Ottawa: Carleton University, 2001.

6 FREIRE, P. Pedagogia do oprimido. 38. ed. Rio de Janeiro: Paz e Terra, 2004.

7 FREIRE, P. SHOR, I. Medo e ousadia. O cotidiano do professor. 9. ed. Rio de Janeiro: Paz e Terra, 2001. p. $122-123$. 
consultivos, propositivos e deliberativos de formulação de políticas públicas, pois dialogar nos é ontológico. Entretanto, deve-se desde já esclarecer que esta garantia não será doação de quem detém as melhores cotas de poder ${ }^{8}$, mas resultado do próprio processo educativo que se dá na participação consciente e enfrentante daquelas/es que se dispõem a atuar na esfera pública.

Desde já, há de se esclarecer também que não paira em nossa compreensão da realidade sociocultural pantaneira que há de existir diálogo verdadeiro (que é práxis) entre antagônicos - pescadora/or tradicional e a indústria energética, p. ex. -, estas pessoas possuem agendas conflitantes, como já dito por Freire não há "nenhuma vinculação dialogal entre estas elites e estas massas [...]". Entendemos, portanto, que, no compromisso com a luta por liberdade, respeito, dignidade humana - por serem mais-, oprimidas/os devem, em solidariedade, estabelecer agendas comuns com seus semelhantes e com as/os diferentes.

Nesse sentido, nossa pesquisa também desenvolveu um processo educativo, já que durante as reuniões, encontros e demais espaços em que estivemos envolvidos não hesitamos em apontar a importância da relação dialógica a ser estabelecida entre os saberes tradicionais pantaneiros e os saberes acadêmicos advindos da racionalidade técnica instrumental. Para tanto, sempre suscitamos que não há de se conceber hierarquias interpretativas da realidade, a ponto de desconsiderar os saberes tradicionais ou os saberes técnicos nos processos de formulação das normas em comento.

Para tanto, em um contexto de conflito socioambiental ${ }^{10}$, também empregamos a Stakeholders Analysis. Os stakeholders são todos aqueles que afetam, e/ou são afetados pelas políticas, decisões, programas e ações. Neste trabalho são assim considerados os grupos que estão influenciando a elaboração das leis de Gestão e de redelimitação do Pantanal de Mato Grosso. Os autores consideram que ela pode ser utilizada para diagnósticos a priori de planos de gestão de recursos, para a avaliação a posteriori deles, para a pesquisa de sistemas de gestão de recursos naturais, e também como uma ferramenta de apoio aos processos de resolução de problemas.

À guisa de esclarecimento, o que foi considerado de maior importância para a escolha desta abordagem metodológica depreende-se de que, através

\footnotetext{
8 Este é um termo cunhado por Little (2004). Consideramos que é importante conhecer as cotas de poder de um determinado grupo ao avaliar um conflito socioambiental, tendo em vista revelar a capacidade de intervenção que aquele grupo tem para implementar seus interesses no âmbito dos espaços públicos de tomada de decisão.

9 FREIRE, P. Educação como prática da liberdade. 22. ed. Rio de Janeiro: Paz e Terra, 1996. p. 55.

10 LITTLE, P. E. Os conflitos sócio-ambientais: um campo de estudo e de ação política. In: BURSZTYN, M. (Org.). A dificil sustentabilidade: política energética e conflitos ambientais. Rio de Janeiro: Ed. Garamond Ltda, 2001.
} 
dela, os interesses dos grupos marginalizados e sem poder sejam considerados durante todo o processo de consulta e nas tomadas de decisão.

Portanto, comprometidos com o referencial teórico-metodológico de uma Pesquisa Participante ${ }^{11}$ estivemos envolvidos ativamente nos diversos ambientes de diálogos em que se tratava da proposta de formulação da Lei Estadual n. 8.830/2008. Em seu magistério, Little ${ }^{12}$ afirma que a identificação e análise dos interesses dos principais atores sociais envolvidos em pesquisas como esta são uma questão fundamental para a compreensão de conflitos socioambientais. O autor considera que:

[...] para perceber um conflito na sua totalidade, o pesquisador tem a obrigação de entender as intenções e posições de todos os atores sociais envolvidos, mesmo que tenha preferência por um dos grupos envolvidos.

Para a identificação dos stakeholders que atuaram na elaboração das leis de Gestão de redelimitação do Pantanal foram utilizados como corpus de análise os seguintes documentos: a) a transcrição da entrevista concedida pela então gerente de Políticas do Pantanal da Secretaria de Meio Ambiente do Estado de Mato Grosso; b) a ata da $7^{\underline{a}}$ Reunião Ordinária do Conselho Estadual de Meio Ambiente (Consema), realizada no dia 26/09/2006; c) a Resolução 50/06 do Consema; Ofício n 558/2006 - Famato; d) a Comunicação Interna nº 085/2006 da Superintendência de Biodiversidade - Gerência de Política do Pantanal de 29/11/2006 e seus anexos; e e) as atas das audiências públicas realizadas pela Assembleia Legislativa do Estado de Mato Grosso nos municípios de Poconé, Cáceres e Barão de Melgaço.

\section{Um breve relato sobre a tramitação das minutas e consultas realizadas}

Para essa contextualização do processo histórico de elaboração das Leis de gestão e redelimitação do Pantanal no Estado de Mato Grosso, foram utilizados o levantamento documental (documentos oficiais, atas das audiências públicas) e a entrevista realizada com a gerente de Políticas do Pantanal da Secretaria Estadual de Meio Ambiente (Sema-MT).

11 FALS BORDA, O. Aspectos teóricos da pesquisa participante: considerações sobre o significado e o papel da ciência na participação popular. In: BRANDÃO, C.R. (Org.) Pesquisa participante. 4. ed. São Paulo: Brasiliense, 1999. p. 42-62.

12 LITTLE, P. E. A Etnografia dos Conflitos Sócio-Ambientais: bases metodológicas e empíricas. In: II ENCONTRO DA ANPPAS, 26 a 29 de maio de 2004. Indaiatuba, São Paulo - Brasil, p. 4. 
Há muito, a sociedade civil, educadoras/es, gestoras/es e pesquisadoras/ es demandam pela proteção jurídica do Pantanal. Identificamos nesse diálogo que há um consenso entre diversos stakeholders de que é necessário que o Estado, a partir de um processo participativo, promova uma legislação protetiva que garanta a conservação da biodiversidade e cultura pantaneiras.

A partir desse diagnóstico inicial, em diálogo com a gerente de Políticas para o Pantanal da Sema, ela relatou que foi a partir da crescente demanda de solicitações para renovação de licenças para as pousadas no Pantanal Mato-grossense e as consequentes dificuldades de se aplicar a legislação federal vigente ao ecossistema pantaneiro, que se deflagrou o processo de elaboração da Lei de Gestão do Pantanal. A entrevistada afirmou que:

[...] inicialmente a Sema tinha uma demanda muito grande de licença de pousadas no Pantanal [...] essas licenças espiraram e precisavam ser renovadas. Nesse processo de renovação a equipe técnica começou, com o passar do tempo, a não ter segurança para emitir as licenças na área do Pantanal, porque se você coloca o que está na legislação o Pantanal todo é uma APP. Precisamos saber que tipo de uso vamos permitir no Pantanal.

Deste modo, a Sema criou, no ano de 2005, um grupo de trabalho (GT) para a elaboração de uma proposta de minuta para a gestão do Pantanal. Fizeram parte deste GT funcionários de diversos setores da secretaria. Com respeito às ações e encaminhamentos deste GT, a gerente ponderou que:

[...] nós realizamos um grupo interno aqui na Sema, tivemos representantes de todos os setores da Sema, esse grupo se reuniu umas oito vezes, oito reuniões, em dois meses de trabalho, [...] apesar de ter representantes de vários setores da Sema, ele foi composto por pessoas recém-concursadas basicamente, os mais antigos não se envolveram tanto com esse trabalho.

Os dados levantados pela gerência e organizados pelo GT - oriundos de reuniões com técnicos do Centro de Pesquisa do Pantanal (CPP), reuniões com a Federação das Indústrias de Mato Grosso (FIEMT); Embrapa Pantanal, e Sindicatos rurais - foram encaminhados à Procuradoria do Meio Ambiente do Estado para que, a partir dessas informações, fosse sistematizada a minuta.

A minuta foi apresentada à sociedade em 5 de maio de 2006 no Forest. Este evento é um congresso bienal, trata-se de uma referência mundial para as áreas Florestal e Ambiental, que tem como finalidade o intercâmbio cientifico e a reunião de especialistas no assunto. Depois de apresentada à comunidade 
acadêmica a minuta ficou à disposição da sociedade civil para que recebesse sugestões no site da Sema. A gerente afirmou que a secretaria recebeu poucas sugestões "palpáveis" via internet, "às vezes uma frase, uma palavra, [...] recebemos muitos comentários pela internet, de coisas palpáveis mesmo foram poucas".

Em 22 de setembro de 2006 a Universidade do Estado de Mato Grosso (Unemat), através de um seminário realizado pelo Programa de Mestrado em Ciências Ambientais no Centro de Pesquisa de Limnologia e Etnoecologia do Pantanal (Celbe), criou um grupo de trabalho (GT) que sistematizou os dados oriundos do seminário apresentando sugestões para o aprimoramento da minuta do projeto de lei.

Destaque-se que o projeto discutido e proposto por estudantes e educadoras/es da Unemat trazia em corpo aspectos relacionados à valorização dos povos e comunidades tradicionais a partir das diretrizes lançadas no contexto da Política Nacional de Povos e Comunidades Tradicionais - Decreto n ${ }^{\circ}$ 6.040, de 7 de fevereiro de 2007 - Política Nacional de Desenvolvimento Sustentável dos Povos e Comunidades Tradicionais.

A proposta abordou, também, temas relacionados à área de abrangência da Lei de gestão, sustentando que em função, especialmente do avanço do agronegócio sobre as nascentes dos principais rios da região, esta lei deveria versar sobre a gestão de toda a Bacia do Alto Paraguai (BAP), e não somente sobre a área alagável - como desde o início defendiam as/os representantes do agronegócio. Propôs, também: a) o impedimento da instalação de empreendimentos altamente impactantes na região (carvoarias, hidrelétricas, usinas de álcool, etc.); c) a criação de um fundo para o financiamento de empreendimentos que fortaleçam a cadeia produtiva local a partir do modelo endógeno de produção; d) a regularização da atividade turística no Pantanal de Mato Grosso; entre outros (Quadro 2). De maneira geral esta proposta partilhada das classes populares contemplava as indicações técnicas dos estudos feitos pela instituição.

Diante desta e de uma série de outras demandas e proposituras, o Conselho Estadual de Meio Ambiente do Estado de Mato Grosso (Consema) criou em 26/09/2006 uma comissão especial, que teve como finalidade analisar e apresentar propostas a estes projetos de lei. A comissão foi composta pelos representantes das seguintes instituições: Federação da Agricultura do Estado de Mato Grosso (Famato); Secretaria de Estado de Indústria, Comércio e Minas e Energia (Sicme); Federação das Indústrias do Estado de Mato Grosso (FIEMT); Instituto Ecológico Sociocultural da Bacia Platina (IESCBAP); Ordem dos Advogados do Brasil (OAB/MT); Secretaria de Estado de Desenvolvimento Rural (Seder); Secretaria 
de Estado de Desenvolvimento de Turismo (Sedtur) e Universidade Federal de Mato Grosso (UFMT), sob a presidência do representante da Famato.

Diferentemente do que demandávamos, as reuniões da comissão foram realizadas no auditório da Famato em Cuiabá, conforme afirmações feitas pelo representante da Ordem dos Advogados do Brasil, na Audiência Pública de Poconé:

[...] então, ficamos, para encerrar, muito envaidecidos, em nome do Conselho Estadual do Meio Ambiente, falo aqui em nome do Vicente Falcão, onde disponibilizou, deputado Homero Pereira, o auditório da Famato, para as nossas reuniões. ${ }^{13}$

A Comissão Especial encaminhou a proposta ao presidente do Consema em 24 de outubro de 2006 através do Ofício nº 558/2006 - Famato ${ }^{14}$. Em seguida este documento foi dirigido ao chefe do Executivo estadual que, de pronto, o encaminhou à Assembleia Legislativa do Estado de Mato Grosso (ALMT), conforme as afirmações do secretário estadual do Meio Ambiente na audiência pública de Poconé:

[...] o governador analisou e resolveu apresentar essa minuta, inclusive para dar uma valorização ao Conselho Estadual de Meio Ambiente, e apresentou essa minuta como mensagem do governo para a Política de Gestão do Pantanal. ${ }^{15}$

É importante ressaltar que, a despeito das indagações, as mensagens encaminhadas pela Comissão Especial presidida pela Famato tramitaram sem uma discussão ampliada do conselho pleno do Consema. Mesmo diante de solicitações feitas por seus membros. Vejamos:

[...] que as propostas reformuladas da Política do Pantanal voltassem à discussão no conselho antes de serem encaminhadas à Assembleia Legislativa para votação. Esclareceu ainda que recebeu várias solicitações de advogados que gostariam de fazer sustentação oral no plenário. ${ }^{16}$

Com a palavra a representante da IFPDS cobrou da Comissão formada por Membros do Pleno sobre a discussão das Políticas para a Gestão do

\footnotetext{
13 Ata da Audiência Pública de Poconé, p. 34.

14 Com exceção das notas taquigráficas das audiências públicas, a cópia de todos os expedientes citados neste artigo estão arroladas em SOUZA, S. C. de. Proteção Jurídica do Pantanal: a construção do marco regulatório no estado de Mato Grosso. 2008. 205p. Dissertação de Mestrado. Programa de pós-graduação em Ciências Ambientais. Unemat, Cáceres, 2008.

15 Ata da Audiência Pública de Poconé, p. 5.

16 Representante da Ordem dos Advogados do Brasil. Ata da $1^{\underline{a}}$ Reunião Ordinária do Conselho Estadual do Meio ambiente (Consema), realizada dia 06/02/2007, linhas: 237-241.
} 
Pantanal, informações sobre o andamento, pois tinha a informação de que já estaria sendo discutido pela Assembleia Legislativa de Mato Grosso e que não mais o assunto seria discutido pelo conselho. ${ }^{17}$

Depois de receber as mensagens do Poder Executivo a Assembleia Legislativa de Mato Grosso (ALMT) realizou audiências públicas nos municípios de Poconé, Cáceres e Barão de Melgaço, respectivamente. Após a realização das audiências a ALMT criou também um grupo de trabalho (GT), presidido pela responsável pelo Núcleo Ambiental. Esse GT tinha por objetivo sistematizar as demandas apresentadas em todos os ambientes de consulta empreendidos até aquele momento.

Assim, como em várias outras reuniões, participamos ativamente deste grupo de trabalho. O GT se reuniu diversas vezes na ALMT, contando com a presença de representantes de vários setores de governo e da sociedade civil. Em todas as reuniões ficaram explícitos os conflitos de interesse atinentes, especialmente, às demandas de agricultoras/es familiares, das comunidades tradicionais pantaneiras e de setores do agronegócio e da mineração.

Os debates eram mediados pela responsável pelo Núcleo Ambiental da ALMT. Como dito, a partir da minuta elaborada pela comissão especial do Consema, este GT foi criado, também, para sistematizar as sugestões oriundas das audiências públicas, todavia é importante frisar que estas atas, apesar de diversas solicitações, nunca foram utilizadas nas reuniões do GT. Outro ponto importante a ser destacado é que, apesar do esforço da coordenação, os trabalhos do GT só ocorreram até a discussão do art. $4^{\circ}$ da minuta que versava sobre a gestão da BAP, lembrando que tal minuta era composta de vinte artigos.

Em 17/11/2006 foi realizada uma reunião na Casa Civil, onde estiveram presentes representantes da Sema e o governador do Estado de Mato Grosso. A partir dos dados sugeridos nessa reunião fora elaborada uma tabela, que foi anexada à Comunicação Interna nº 85/2006 da Superintendência de Biodiversidade - Gerência de Política do Pantanal, de 29/11/2006. Em sua primeira coluna está disposta a versão da minuta com contribuições acatadas pela Gerência de Políticas do Pantanal da Superintendência de Biodiversidade da Sema; na segunda coluna as decisões realizadas pelo governador; e na terceira as sugestões do Consema, não acatadas pelo GT.

Quanto aos encaminhamentos desta reunião, é importante destacar que o governador do Estado sugeriu, desde então, que a legislação não versasse

17 Representante do Instituto Floresta de Pesquisa e Desenvolvimento Sustentável. Ata da $2^{\underline{a}}$ Reunião Ordinária do Conselho Estadual do Meio ambiente (Consema), realizada dia 20/03/2007, linhas: 326-330. 
sobre todo o Pantanal - que fosse restrita à área alagável; também reiterou as demais demandas atinentes aos pleitos dos setores vinculados ao agronegócio mato-grossense.

Em 15 de agosto de 2007, como parte da pesquisa desenvolvida, uma entrevista foi realizada nas dependências da Gerência de Políticas do Pantanal da Sema. Na oportunidade, a gerente afirmou que o que desencadeou o interesse em elaborar uma Lei de gestão para o Pantanal foi o "aumento da demanda por renovação de licenças das pousadas no Pantanal”, afirmou também que as/os técnicas/os da Sema não estavam mais sentindo segurança para emitir as renovações a partir da legislação em vigor, pois, "se fossem levar ao pé da letra tudo no Pantanal era área de preservação permanente”.

Com respeito aos grupos que atuaram na elaboração da minuta de lei que foi apresentada pela Sema no Forest de 2006, a gerente citou a Sema, o Centro de Pesquisa do Pantanal (CPP); a Embrapa Pantanal e a Procuradoria-Geral do Estado de Mato Grosso.

A partir do $1^{\circ}$ Fórum Estadual de Meio Ambiente [...], que era subdividido por temas, por biomas, e esse fórum tinha um grupo de trabalho de políticas para o Pantanal, desse fórum saíram várias contribuições, de diversos segmentos, considerando todas as questões que precisávamos resolver, e esse evento [...] e os outros que nós havíamos participado. [...] Nós pegamos então todos os materiais do Fórum do meio ambiente, pegamos os estudos do GEF, PCBAP, técnicos da Sema e um representante da Embrapa Pantanal, nós elaboramos o que nós entendíamos que poderia ser permitido no Pantanal [...].

De acordo com a gerente, foi no período em que a minuta esteve no site da secretaria para discussão que o GT da Sema recebeu propostas de emendas elaboradas, também, por outras instituições. No que tange à participação da sociedade pela internet, a entrevistada avaliou que a sociedade não entendeu inicialmente a proposta. Segundo ela:

[...] primeiro tem que relatar que a sociedade não entendeu muito bem esse processo, muitos entenderam que era uma minuta já pronta que já estava resolvido, e que mais uma vez era uma lei sendo imposta de cima para baixo, nós tivemos todo um trabalho de informar às pessoas que não era essa a intenção, a proposta podia estar errada, mas o que a gente queria era receber contribuições [...]. 
Note-se que, além da dificuldade de acesso à internet dos povos e comunidades residentes nessa região do estado de Mato Grosso, avaliamos conjuntamente que, muito provavelmente, isso tenha ocorrido tendo em vista que a gênese da proposta de lei está vinculada a interesses fiscalizatórios. Como reiterado por representantes dessas comunidades pantaneiras em todas as audiências públicas e nos GTs em que participamos, apesar dos avanços possíveis, a proposta de lei surgiu para implementar as atividades técnicas de fiscalização do Estado e não como política pública garantidora de direitos, oriunda dos interesses elementares das camadas populares da sociedade pantaneira.

Nesse processo, restou-nos manifesto, a partir do diálogo com a responsável direta pela condução das políticas públicas para o Pantanal de Mato Grosso que, apesar dos esforços de algumas/ns técnicas/os da Sema e de outros setores da esfera pública estatal, a modalidade de consulta virtual, apesar de importante, não logrou o êxito pretendido. Isto está vastamente demonstrado nos relatos feitos pela entrevistada durante as reuniões e encontros oficiais em que nos reunimos para tratar dessa temática.

\section{Participação nas audiências públicas: demandas e encaminhamentos do Estado/Mercado}

No contexto desta pesquisa, a participação plena é, antes de tudo, uma conquista socia $^{18}$. Nesse sentido, participar significa intervir num processo decisório qualquer, conforme nos lembram Morón ${ }^{19}$ e Duarte $^{20}$. A participação pressupõe diálogo e democratização das instâncias deliberativas ${ }^{21}$.

O princípio 10 da Declaração do Rio afirma que "a melhor maneira de tratar questões ambientais é assegurar a participação, no nível apropriado, de todos os cidadãos interessados. [...]”22. É nessa perspectiva que, a partir do que identificamos em nossas atividades de pesquisa, pretendemos contextualizar a importância dos mecanismos de participação pública, em especial as audiências públicas que trataram das normas em comento.

18 DEMO, P. Participação é conquista: noções de política social participativa. 3. ed. São Paulo: Cortez, 1996.

19 MÓRON, M. S. La Participación del Ciudadano en la Administración Pública. Madrid, Centro de Estudios Constitucionales, 1980.

20 DUARTE, D. Procedimentalização, Participação e Fundamentação: para uma concretização do princípio da imparcialidade administrativa como parâmetro decisório. Coimbra: Ed. Almedina, 1996.

21 IRIGARAY, C. T. J. H. A Gestão Sustentável dos Recursos Hidricos no Brasil, um Direito Humano Fundamental. 2003. Tese (doutorado)- Universidade Federal de Santa Catarina, Centro de Ciências Jurídicas. Programa de Pós-Graduação em Direito, 2003.

22 ORGANIZAÇÃO DAS NAÇÕES UNIDAS. Declaração do Rio sobre Meio Ambiente e Desenvolvimento. 
Destaque-se que, ao lado da participação nos órgãos colegiados dotados de poder normativo - conselhos consultivos e deliberativos que tratam de temas socioambientais (Conama, Consema, etc.) - e, especialmente, com o advento das normas que regulamentam a Política Nacional do Meio Ambiente, as audiências públicas tornaram-se um importante espaço de manifestação propositiva das demandas dos grupos de interesse historicamente excluídos dos processos decisórios.

Para Milaré ${ }^{23}$ a audiência pública é o instrumento de garantia mais importante para o exercício dos princípios da publicidade e da participação pública. Para tanto é necessário que as/os participantes estejam preparadas/os - providas/os de informações de qualidade técnica e do saber tradicional correlato - para participar efetivamente e que haja compromisso ético, por parte das/ os gestoras/es da coisa pública, em garantir, na política pública, as demandas que não firam, por exemplo, direitos humanos fundamentais.

No caso em tela, as audiências públicas ocorreram nos municípios de Poconé, em 26 de março de 2007; Cáceres, em 13 de abril de 2007; e Barão de Melgaço, em 16 de abril de 2007. Tiveram como objetivo discutir as Mensagens n 2/07, que dispõe sobre a Política Estadual de Gestão do Pantanal de Mato Grosso; e n 3/07, que dispõe sobre os limites do Pantanal no estado de Mato Grosso. Os quadros 1 e 2, abaixo arrolados, demonstram algumas das principais demandas apresentadas por agentes de mercado e por representantes de setores comunitários/sociedade civil organizada que participaram ativamente das audiências públicas.

\section{Demandas apresentadas por representantes do Mercado}

\begin{tabular}{|c|c|}
\hline 1 & $\begin{array}{l}\text { Cerca de } 90 \% \text { das/os representantes pleitearam que a Lei de Gestão fosse } \\
\text { limitada somente à área alagável da Bacia do Alto Paraguai }\end{array}$ \\
\hline 2 & Flexibilização nos processos de licenciamento ambiental \\
\hline 3 & $\begin{array}{l}\text { "Limpeza" de pastagem como supressão das seguintes espécies: Pombeiro } \\
\text { (Combretum lanceolatum e Combretum laxum), Canjiqueira (Byrsonima } \\
\text { orbignyana), Pateiro (Couepia uiti), Pimenteira (Licania parvifolia), Cambará } \\
\text { (Vochisia divergens), Algodoeiro (Ipomoea fistulosa) }\end{array}$ \\
\hline 4 & Construção/implantação das usinas de álcool na região \\
\hline 5 & $\begin{array}{l}\text { Sugeriram que o estado de Mato Grosso não tem competência para legislar } \\
\text { sobre o Pantanal, inclusive demandaram para que não ocorresse mais } \\
\text { audiências públicas além de Poconé }\end{array}$ \\
\hline
\end{tabular}

Continua...

23 MILARÉ, E. Direito do Ambiente: doutrina - jurisprudência - glossário. 3. ed. São Paulo: RT, 2000. p. 461-462. 


\begin{tabular}{c|l}
\hline 6 & $\begin{array}{l}\text { Implementação da hidrovia Paraguai-Paraná e a construção de portos nos rios } \\
\text { do Pantanal }\end{array}$ \\
\hline 7 & $\begin{array}{l}\text { Cultivo de transgênicos na BAP, bem como o seu transporte nos rios que a } \\
\text { compõe. }\end{array}$ \\
\hline 8 & $\begin{array}{l}\text { Demandaram por mais financiamento para agronegócio da região, } \\
\text { especialmente para o avanço de monoculturas sobre áreas de pastagens }\end{array}$ \\
\hline 9 & Instalação de projetos hidrelétricos na BAP \\
\hline 10 & $\begin{array}{l}\text { Defenderam os empreendimentos ligados à mineração e implantação } \\
\text { carvoarias na região }\end{array}$ \\
\hline
\end{tabular}

Quadro 1 - Exemplos de demandas apresentadas nas audiências públicas por representantes do Mercado

\begin{tabular}{c|l}
\hline \multicolumn{1}{c}{ Demandas apresentadas por representantes dos setores comunitários/sociedade } \\
civil organizada
\end{tabular}

Quadro 2 - Exemplos de demandas apresentadas nas audiências públicas por representantes dos setores comunitários/sociedade civil organizada

Verifica-se aí um manifesto conflito socioambiental. As demandas apresentadas pelos representantes do mercado são, em sua maioria, diametralmente opostas aos pleitos propostos pelos setores vinculados às classes populares oriundas da sociedade pantaneira mato-grossense. Há uma evidente disposição em estabelecer uma relação dialógica entre as/os representantes dos setores populares, entretanto 
é evidente que setores vinculados ao mercado/capital possuem agendas distintas das agendas dos setores populares. Como dito por Loureiro ${ }^{24}$ :

[...] ignorar a existência de conflitos na busca de consensos é definir uma posição ideológica de defesa do diálogo para a resolução dos riscos, sem considerar as desigualdades que marcam necessidades radicalmente distintas em uma sociedade de classe.

Portanto, há que se considerar - pelo menos em tese -, a importância das audiências públicas como espaço legítimo de explicitação de demandas dos diferentes setores envolvidos nas discussões que tratam também das temáticas socioambientais. Todavia, cumpre ressaltar que, para que essa participação não seja simplesmente legitimadora dos interesses de setores de mercado, ela precisa ser lúcida, permanente, qualificada e propositiva. Deve-se garantir, a partir dela, que os temas tratados sejam revisitados permanentemente.

Ao contrário do que fora demandado por representantes de mercado, as proposituras feitas por setores populares que participaram das audiências públicas demandaram majoritariamente pela inegociável defesa dos povos e comunidades tradicionais pantaneiras; sustentam que a legislação deve garantir a estas populações seu desenvolvimento pleno a partir dos modelos alternativos ao imposto pelo capital.

Outro ponto importante, verificado nas sugestões, é a crítica ao modelo hegemônico de exploração ambiental em Mato Grosso, apontado como concentrador, alicerçado no latifúndio, e consequentemente excludente, e altamente impactante do ponto de vista ecológico.

Diante disso, contrastando as demandas apresentadas nestes espaços de debate público com os termos da Política Estadual de Gestão e Proteção à Bacia do Alto Paraguai no Estado de Mato Grosso e o veto da proposta legislativa que versava sobre os limites do Pantanal no estado de Mato Grosso, restou-nos evidente que, apesar da participação demandante e contextualizada com a realidade socioambiental pantaneira de diversas/os representantes de povos e comunidades tradicionais pantaneiras, da sociedade civil organizada, das instituições de ensino superior de Mato Grosso, de instituições de extensão e pesquisa e de órgãos de Estado das três esferas de poder, prevaleceu majoritariamente - na norma sancionada e nas razões de veto da norma de redelimitação - os interesses dos setores de mercado, especialmente os interesses apresentados pelo agronegócio mato-grossense.

24 LOUREIRO, C. F. B. O Movimento Ambientalista e o Pensamento Crítico: uma abordagem política. Rio de Janeiro: Quartet, 2003. p. 125. 


\section{Algumas considerações}

Como dito, após o período de discussão nos grupos de trabalho e da tramitação na ALMT, o governador sancionou a Lei de gestão e vetou o projeto que estabelecia os novos limites para o Pantanal de Mato Grosso. Sobre o veto o Executivo argumentou que, "trata-se de um erro material", já que a delimitação proposta traria inúmeras consequências negativas. O governador afirma que "o Pantanal Mato-grossense é uma realidade, independentemente da delimitação que lhe for dada”.

Nas motivações do veto o governador afirma que "não é o fato de não estabelecer em lei estadual os seus exatos limites que deixaria o ecossistema desprotegido". Argumentos que, a nosso ver, explicitam os interesses do agronegócio mato-grossense, no que diz respeito ao avanço sobre as áreas de entorno da BAP.

Como apontado por Souza e Irigaray ${ }^{25}$, de maneira geral a norma sancionada é muito semelhante à proposta defendida pelos representantes dos setores vinculados ao agronegócio do estado de Mato Grosso. Nela o gestor estadual, além de assentir majoritariamente com as demandas desse setor, perde a oportunidade de estabelecer, de fato, a bacia hidrográfica como unidade de planejamento e gestão territorial para o Pantanal no estado de Mato Grosso.

Apesar disso, ocorreram, sem dúvidas, alguns avanços no decorrer do processo de discussão. Avanços estes que - além dos processos educativos decorrentes da participação propriamente dita - podem ser observados a partir da inserção de conceitos, princípios, diretrizes e algumas vedações de uso, que deverão orientar de modo participativo e decisivo as políticas públicas a serem implementadas na região.

Exemplo disso diz respeito à definição das áreas protegidas, o que inclui a novel categoria de áreas de conservação permanente. Sobre este tema a legislação fez um alinhamento com a realidade do Pantanal de Mato Grosso estabelecendo conceitos efetivamente aplicáveis no aparato legal, fazendo alusão a aspectos específicos da região, quando regulamenta a proteção de ecossistemas presentes no bioma pantaneiro, a exemplo dos corixos, veredas, campos inundáveis, brejos, meandros de rios, capões de mato e murunduns.

Entretanto, a aplicação destes dispositivos e demais conquistas empreendidas na norma somente acontecerão se, desde logo, os movimentos populares da sociedade civil - detentores de menores cotas de poder legislativo - permanecerem vigilantes e empreenderem dialogicamente todos os esforços

25 SOUZA, S. C. de; IRIGARAY, C. T. J. H. Comentários à lei de gestão do Pantanal de Mato Grosso. Amazônia Legal, v. 2, n. 4, p. 41-59, 2008. 
no sentido de cobrarem efetivamente o cumprimento das disposições legais conquistadas, devendo, ainda, sustentar diligente e tenazmente a retomada do diálogo entre o poder público e a sociedade sobre as demandas propositadamente silenciadas na legislação vigente.

Enfim, como já apontado, no contexto desta pesquisa, a participação é, antes de tudo, conquista sociale práxis que objetiva desvelar a realidade para que as pessoas envolvidas no processo dialógico possam juntas transformá-la objetivando a elaboração coletiva e solidária de caminhos que possibilitem a construção de uma sociedade sustentável. Resta-nos evidente que, para a consecução de uma norma de âmbito nacional que pretenda proteger o bioma pantaneiro, esta deve inarredavelmente ser fruto de um amplo processo efetivamente participativo.

Ao contrário do que, em grande medida, fora identificado na norma estadual (Lei 8.830/2008), importa que o dispositivo federal não carregue em si o esvaziamento sociocultural identificado na norma estadual. Que para além do conjunto de conceitos, diretrizes e princípios, consideramos importante que a norma federal aponte caminhos que garantam a proteção das funções ecossistêmicas e respectivos serviços ambientais, a partir da multiplicidade cultural característica do Pantanal Mato-grossense.

\section{Referências}

BRANDÃO, C. R. Repensando a Pesquisa Participante. São Paulo: Brasiliense, 1999.

BRASIL. Decreto n ${ }^{\circ} 6.040$, de 7 de fevereiro de 2007. Institui a Política Nacional de Desenvolvimento Sustentável dos Povos e Comunidades Tradicionais. Disponível em: < http://www.planalto.gov.br/ ccivil_03/_ato2007-2010/2007/decreto/d6040.htm > Acesso em: 6 jun. 2007.

Lei $\mathrm{n}^{\circ}$ 6.938, de 31 de agosto de 1981. Dispõe sobre a Política Nacional do Meio Ambiente. Disponível em: < http://www.planalto.gov.br/ccivil 03/LEIS/L6938.htm >Acesso em: 20 out. 2006.

Senado Federal. Projeto de Lei 750, de 20 de dezembro de 2011. Dispõe sobre a Política de Gestão e Proteção do Bioma Pantanal. Disponível em: < http://www25.senado.leg.br/web/atividade/ materias/-/materia/103831 > Acesso em: 9 mai. 2013.

CHEVALIER, J. Stakeholder analysis and natural resource management. Ottawa: Carleton University, 2001. Disponível em: http://www1.worldbank.org/publicsector/politicaleconomy/November3Seminar/Stakehlder\%20Readings/SA-Chevalier.pdf > Acesso em: 6.mar. 2007.

DEMO, P. Participação é conquista: noções de política social participativa. 3. ed. São Paulo: Cortez, 1996.

DUARTE, D. Procedimentalização, Participação e Fundamentação: para uma concretização do princípio da imparcialidade administrativa como parâmetro decisório. Coimbra: Ed. Almedina, 1996.

FALS BORDA, O. Aspectos teóricos da pesquisa participante: considerações sobre o significado e o papel da ciência na participação popular. In: BRANDÃO, C.R. (Org.) Pesquisa participante. 4. ed. São Paulo: Brasiliense, 1999. p. 42-62. 
FREIRE, P. Criando métodos de pesquisa alternativa. Aprendendo a fazê-la através da ação. In: BRANDÃO, C. R. (Org.). Pesquisa participante. 4. ed. São Paulo: Brasiliense, 1999. p. 34-41.

. Educação como prática da liberdade. 22. ed. Rio de Janeiro: Paz e Terra, 1996.

. Pedagogia da esperança: um reencontro com a pedagogia do oprimido. 12. ed. Rio de

Janeiro: Paz e Terra, 2005.

. Pedagogia do oprimido. 38. ed. Rio de Janeiro: Paz e Terra, 2004.

. SHOR, I. Medo e ousadia. O cotidiano do professor. 9. ed. Rio de Janeiro: Paz e Terra. 2001.

GRIMBLE, R; CHAN, M-K. Stakeholder analysis for natural resource management in developing countries. In: Natural resources forum. Blackwell Publishing Ltd., 1995. p. 113-124.

IRIGARAY, C. T. J. H. A Gestão Sustentável dos Recursos Hídricos no Brasil, um Direito Humano Fundamental. 2003. Tese (doutorado)- Universidade Federal de Santa Catarina, Centro de Ciências Jurídicas. Programa de Pós-Graduação em Direito, 2003.

LITTLE, P. E. A Etnografia dos Conflitos Sócio-Ambientais: bases metodológicas e empíricas. In: II ENCONTRO DA ANPPAS, de 26 a 29 de maio de 2004, Indaiatuba - São Paulo - Brasil.

. Os conflitos sócio-ambientais: um campo de estudo e de ação política. In: BURSZTYN, M. (Org.). A dificil sustentabilidade: política energética e conflitos ambientais. Rio de Janeiro: Ed. Garamond Ltda., 2001.

LOUREIRO, C. F. B. O Movimento Ambientalista e o Pensamento Crítico: uma abordagem política. Rio de Janeiro: Quartet, 2003.

MATO GROSSO. Lei n 8.830, de 21 de janeiro de 2008. Institui a Política Estadual de Gestão e Proteção à Bacia do Alto Paraguai no Estado de Mato Grosso. Disponível em: < http://www.al.mt. gov.br/storage/webdisco/leis/lei_4702.pdf > Acesso em: 15 set. 2007.

MILARÉ, E. Direito do Ambiente: doutrina - jurisprudência - glossário. 3. ed. São Paulo: RT, 2000.

MÓRON, M. S. La Participación del Ciudadano en la Administración Pública. Madrid: Centro de Estudios Constitucionales, 1980.

ORGANIZAÇÃO DAS NAÇÕES UNIDAS. Declaração do Rio sobre Meio Ambiente e Desenvolvimento. Disponível em: < http://www.onu.org.br/rio20/img/2012/01/rio92.pdf > Acesso em: 15 abr. 2007.

SOUZA, S. C. de. Proteção Jurídica do Pantanal: a construção do marco regulatório no estado de Mato Grosso. 2008. 205p. Dissertação (Mestrado)-Programa de pós-graduação em Ciências Ambientais. Unemat, Cáceres: 2008.

. IRIGARAY, C. T. J. H. Comentários à lei de gestão do Pantanal de Mato Grosso. Amazônia Legal, v. 2, n. 4, p. 41-59, 2008.

SOUZA, S. C. de; LOGAREZZI, A. J. M. Educação ambiental dialógico-crítica com comunidades tradicionais no Pantanal de Mato Grosso: a solidariedade e os enfrentamentos nas práticas sociais. Ambiente e Educação, Revista de Educação Ambiental, 2016, no prelo. 